\title{
Pyrophosphate heart scan in patients with progressive systemic sclerosis
}

\author{
FRANTIŠEK DUŠKA, PETR BRADNA, JAN NOVÁK, JIŘÍ KUBÍČEK, \\ JAROSLAV VIŽĎA, PETR KAFKA, YVONA MAZUROVÁ, \\ VLADISLAV BLAHA
}

From the Department of Normal and Pathological Physiology, Division of Nuclear Medicine, Department of Radiology, and Chair of the 2nd Department of Medicine, Charles University Caculty of Medicine, Hradec Králové, Czechoslovakia

SUMMARY Scintigraphic examination of the myocardium, using ${ }^{99 m}$ Tc-labelled pyrophosphate, $\overrightarrow{\dot{\theta}}$ was carried out in 17 patients suffering from systemic sclerosis. This connective tissue disorder very 을 often affects the myocardium secondarily. The results of the cardiac scan were compared with the information obtained from the electrocardiogram of systolic time intervals. In addition, spirometry was undertaken to detect a potential relation between cardiac and pulmonary involvement. The scan was found to be positive in seven patients and electrocardiographic findings were pathological in five patients only. The systolic time intervals were abnormal in three patients only. A ventilation $\vec{\bullet}$ disturbance was recorded in 10 patients. No clear relation was found between the results of the individual examinations. It is concluded that pyrophosphate heart scintigraphy may detect myocardial impairment in some cases of systemic sclerosis before it is manifested by heart failure. Examination of systolic time intervals is of little importance.

Scintigraphic myocardial imaging using ${ }^{9_{\mathrm{m}}} \mathrm{Tc}$-labelled pyrophosate has recently become a standard procedure in some hospitals. This diagnostic method has proved useful especially in the detection of acute myocardial infarction. ${ }^{1}$ The accumulation of the radiopharmaceutical in heart tissue, however, is not specific for fresh necrosis. Positive scintigraphic findings have been reported in a number of other heart diseases..$^{2-5}$ Hitherto, there has been very little experience with pyrophosphate heart scanning in cardiomyopathies. Only a few papers concerning this have been published to date, with conflicting results. ${ }^{6-8}$ The introduction of new diagnostic methods in cardiomyopathies is important, as the recognition of these using present techniques is often difficult. Our group, therefore, has studied pyrophosphate cardiac scanning in various cardiomyopathies.

The results obtained from 17 patients suffering from progressive systemic sclerosis are presented. It is well known that diffuse scarring of the myocardium is a late finding in patients with this disease. This change leads to low cardiac output and death resulting from sudden arrhythmias or congestive heart failure. The results of the pyrophosphate heart scan were compared with the findings obtained from a study of Accepted for publication 6 April 1981 systolic time intervals. As progressive pulmonary fibrosis, with obliteration of the pulmonary capillary bed, may occur, and often leads to pulmonary hypertension and cor pulmonale, ventilation disturbances were also sought.

\section{Subjects and methods}

Our series consisted of 17 patients in whom progressive systemic sclerosis was diagnosed using histological examination of a sample of affected skin. There were 13 female and four male patients aged from 20 to 77 years, average 52 years. All patients underwent physical examination; temperature was measured and urine and blood were routinely tested.

Scintigraphic examination was carried out using a Pho/Gamma HP scintillation camera (Nuclear 0 Chicago) with a high resolution collimator. During scintigraphic observation anteroposterior, left anterior oblique, and left lateral projections werc $Q$ used. Two hours before the start of the scintigraphic observation, ${ }^{99 m}$ Tc-labelled pyrophosphate $(370 \stackrel{+}{+}$ $\mathrm{MBq} / 10 \mathrm{mCi}$ ) was given intravenously. An analogue

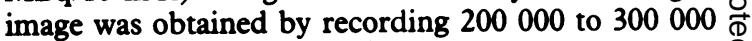
counts on a film of Polaroid type. The digital image $\stackrel{\odot}{\stackrel{\oplus}{*}}$ was obtained by recording the data on a CDS 4096 
channel analyser. The intensity of the ${ }^{9 m} \mathrm{Tc}$-pyrophosphate uptake was graded from 0 to 4+ according to the method of Parkey et al. ${ }^{10}$

Heart rate, the total duration of systole, pre-ejection as well as ejection phases, mechanical systole, and QT interval were obtained. The quotient was calculated using the formula: pre-ejection phase divided by ejection phase. The systolic time intervals were obtained from a simultaneous electrocardiogram (lead II), phonocardiogram, and carotid pulse trace on a direct writing EK 21 Hellige multiscriptor. The paper speed was $50 \mathrm{~mm} / \mathrm{s}$. Systole was measured from the Qwave on the electrocardiogram to the second sound on the phonocardiogram. The ejection phase was determined as the distance from the upstroke of the carotid pulse to the lowest point in its incisura. The preejection phase was calculated as the difference between total systole and ejection phase. Patients were studied, fasting, always at the same time in the morning. After one hour's rest in a lying position the measurements were taken and a mean of 10 cardiac contractions calculated. To eliminate the influence of rate the values obtained were correlated using Weissler's indices. The results of the systolic time interval examination were summarised and labelled as "normal" or "pathological".

All patients were examined spirometrically. The vital capacity, timed expiration curve, and percentage vital capacity in the first second were measured. We also determined whether the ventilation of the lungs was normal or whether an obstructive, restrictive, or mixed ventilation disturbance was involved.

\section{Results}

The results are summarised in Table 1 . It can be seen that the most frequent positive finding in the examination of the heart was that found on the myocardial scan. A pathological scan was recorded in seven patients; in 10 the scintigraphic image was normal.

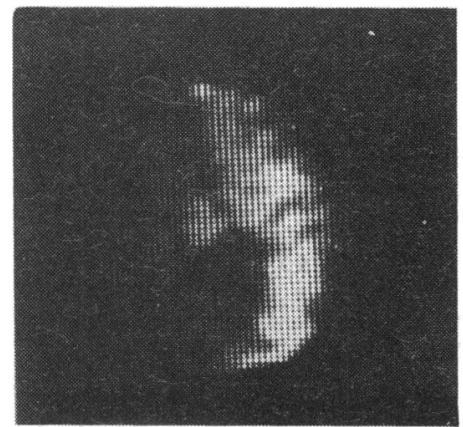

Fig. 1 Pyrophosphate myocardial scan of case 7 with systemic scleroderma. Focal pathological activity 2+. Left lateral projection.

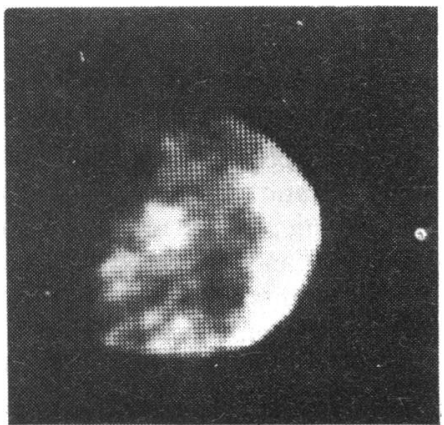

Fig. 2 Pyrophosphate myocardial scan of case 4 with systemic scleroderma. Diffuse pathological activity 3+. Left lateral projection.

Table 1 Results of pyrophosphate heart scan, electrocardiogram, systolic time intervals, and spirometry

\begin{tabular}{|c|c|c|c|c|c|c|}
\hline Case No. & Sex & Age & Scan & Electrocardiogram & $S T I$ & $\begin{array}{l}\text { Abnormality of } \\
\text { Ventilation }\end{array}$ \\
\hline 1 & $\mathbf{F}$ & 63 & Normal & Ventricular extrasystoles & Normal & Mixed \\
\hline 2 & $\mathbf{F}$ & 71 & Normal & Normal & Normal & Normal \\
\hline 3 & $\mathbf{M}$ & 68 & Normal & Normal & Normal & Normal \\
\hline 4 & $\mathbf{M}$ & 64 & $3+$ diffuse & Normal & Normal & Restrictive \\
\hline 5 & $\mathbf{F}$ & 57 & Normal & Normal & Normal & Normal \\
\hline 6 & $\mathbf{F}$ & 46 & Normal & Incomplete right bundle-branch block & Normal & Normal \\
\hline 7 & $\mathbf{F}$ & 72 & $2+$ focal & Normal & Normal & Mixed \\
\hline 8 & $\mathbf{F}$ & 54 & Normal & Atrial extrasystoles & Normal & Mixed \\
\hline 9 & $\mathbf{F}$ & 49 & $2+$ diffuse & Ventricular extrasystole inversion $T$ in $V_{1}-V_{4}$ & Pathological & Mixed \\
\hline 10 & $\mathbf{M}$ & 25 & Normal & Normal & Pathological & Mixed \\
\hline 11 & $\mathbf{F}$ & 38 & $2+$ focal & Normal & Normal & Normal \\
\hline 12 & $\mathbf{F}$ & 39 & $2+$ focal & Normal & Normal & Mixed \\
\hline 13 & $\mathbf{F}$ & 56 & Normal & Normal & Pathological & Mixed \\
\hline 14 & $\mathbf{M}$ & 20 & Normal & Complete right bundle-branch block & Normal & Restrictive \\
\hline 15 & F & 77 & $3+$ focal & Normal & Normal & Mixed \\
\hline 16 & $\mathbf{F}$ & 50 & Normal & Normal & Normal & Normal \\
\hline 17 & $\mathbf{F}$ & 33 & $2+$ focal & Normal & Normal & Normal \\
\hline
\end{tabular}

STI, systolic time intervals. 
The focus of increased activity was $3+$ (diffuse) in case 4 and $2+$ (circumscribed) in cases $7,9,11$, and 12 (Table 1). Examples of positive scintigraphic findings can be seen in Fig. 1 and 2. The electrocardiogram disclosed pathological findings in five patients, but these were not specific. In 12 cases the electrocardiogram was normal. Systolic time intervals contributed least; only three positive results were recorded, and in 14 cases results were normal. Spirometry showed a disturbance of ventilation in 10 patients, which was either of a mixed or restrictive type. The number of positive and negative findings in all examinations carried out is compared in Table 2.

Table 2 Comparison of number of positive and negative findings

\begin{tabular}{lrr}
\hline & Positive & Negative \\
\hline Scan & $7(41 \%)$ & $10(59 \%)$ \\
Electrocardiogram & $5(29 \%)$ & $12(71 \%)$ \\
Systolic time intervals & $3(18 \%)$ & $14(82 \%)$ \\
Spirometry & $10(59 \%)$ & $7(41 \%)$ \\
\hline
\end{tabular}

A mutual comparison of positive findings in individuals is more important that their absolute numbers. All four examinations yielded a positive result in one woman only (case 9). In nine patients at least two examinations were positive. Most frequently the results of the scan and spirometry concurred, both examinations yielding positive results in four patients. Electrocardiography and spirometry showed positive findings in three patients. Agreement between systolic time intervals and spirometry was seen in two cases. There was no agreement between the scan and the electrocardiogram or between the scan and systolic time intervals in any patient. In summary, each of the methods of study yielded some positive findings, but there was no clear relation between them.

\section{Discussion}

The interpretation of the findings is difficult. Necropsy or biopsy of the myocardium was not carried out in any patients, so we do not know how many had myocardial involvement by scleroderma. Nevertheless, it can be assumed on the basis of the results that, if a positive scintigraphic pyrophosphate scan is found, involvement of the heart in scleroderma can be presumed in patients where this is not clinically evident. In patients with heart failure such studies add nothing, because the involvement of the heart is already evident. Systolic time intervals seem of little help. Unfortunately, echocardiography could not be carried out; a comparison of this with the scintigraphic and electrocardiographic findings would be interesting. Spirometry, indicating possible involvement of the lungs, did not correlate closely with the cardiac results and is no guide to cardiac involve- ment; unfortunately we did not measure the diffusing capacity of these patients. Thus, of all these, only the pyrophosphate scan and the electrocardiography proved useful in the early detection of cardiac involvement in scleroderma. In this context the discrepancy $\frac{5}{\sigma}$ between the two is surprising.

The interpretation of scintigraphic findings is dif- $\frac{\widehat{D}}{\mathrm{D}}$ ficult because we do not know enough about the behaviour of ${ }^{9 m} \mathrm{Tc}$-labelled pyrophosphate in damaged myocardium. According to current thinking, the $\vec{\circ}$ pyrophosphate accumulates in the damaged cardiac $\overrightarrow{\vec{H}}$ muscle if the following three conditions are fulfilled ${ }^{11}: \stackrel{\omega}{\circ}$ (1) at least some fresh necrotic tissue must be present; (2) the blood flow through the region affected must be partially preserved; and (3) intramitochondrial cal- . cium phosphate inclusions must be present. A bond $\overrightarrow{0}$ of the radiopharmaceutical to these inclusions is assumed. Other authors, however, do not agree with $\frac{}{7}$ the above hypothesis and assume a bond of the $\vec{c}$ radiopharmaceutical to denatured proteins of damaged myocardial cells. ${ }^{12}$ The fact that positive scintigraphic findings occur in fresh lesions only is of $\underset{2}{2}$ fundamental importance. This implies that myocar- $\overrightarrow{0}$ dial involvement in scleroderma can be diagnosed by scintigraphy only while the disease is active, but not retrospectively. This could account for the discrepancy between the electrocardiographic and scintigraphic findings in our patients. Of course, all this is based on theoretical studies dealing with acute myocardial infarction, not with cardiomyopathies, but we believe these observations on the pyrophosphate cardiac scan in scleroderma to be original.

\section{References}

1 Wynne J, Holman BL. Acute myocardial infarct scintigraphy with infarct-avid radiotracers. Med Clin North Am 1980; 64: 119-44.

2 Davison R, Spies SM, Przybylek J, Hai H, Lesch M. Technetium - 99m stannous pyrophosphate myocardial scintigraphy after cardiopulmonary resuscitation with cardioversion. Circulation 1979; 60: 292-6.

3 O'Rourke R, Righetti A, Schelbert H, Daily P, Ashburn D W, Ross J Jr. Usefulness of pre- and postoperative Tc-99m-pyrophosphate scans in cardiac surgical patients $\tilde{N}$ (abstract). Am f Cardiol 1976; 37: 161.

4 Wald RW, Sternberg L, Huckell VF, Staniloff H, N Feiglin DHI, Morch JE. Technetium-99m stannous N pyrophosphate scintigraphy in patients with calcifica- $\sigma$ tions within the cardiac silhouette. Br Heart $\mathcal{F}$ 1978; 40: 547-51.

5 Dymond DS, Britton KE, Jarritt PH, Langley D, $\mathbb{D}$ Spurrell RAJ. Positive myocardial scintigraphy at the $\stackrel{+}{+}$ bedside-evaluation using a portable gamma camera. Post- $\frac{T}{T}$ grad Med F 1978; 54: 641-8.

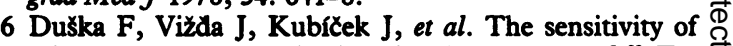
scintigraphic myocardial imaging by the use of ${ }^{9 m} \mathrm{Tc}-\mathbb{D}$ labelled pyrophosphate in the diagnosis of cardiomy- 
opathy of various etiology. Eur $\mathcal{F}$ Nucl Med 1979; 4: 87-90.

7 Perez LA, Hayt DB, Freeman LM. Localisation of myocardial disorders other than infarction with ${ }^{99 \mathrm{~m}} \mathrm{Tc}$ labeled phosphate agents. $f \mathrm{Nucl} \mathrm{Med} \mathrm{1976;} \mathrm{17:} \mathrm{241-56.}$

8 Muz J, Wizenberg T, Samlowski W, Sohn Y. Myocardial uptake of Technetium - $99 \mathrm{~m}$ pyrophosphate in patients with amyloidosis (abstract). $\mathcal{F}$ Nucl Med 1980; 21: P49.

9 Smiley JD. Rheumatic fever, collagen disease and the heart. In: Willerson JT, Sanders CA, eds. Clinical cardiology. New York: Grune \& Stratton, 1977: 248-56.

10 Parkey RW, Bonte FJ, Meyer SL, et al. A new method for radionuclide imaging of acute myocardial infarction in humans. Circulation 1974; 50: 540-6.
11 Buja LM, Parkey RW, Stokely EM, Bonte FJ, Wilerson JT. Pathophysiology of Technetium - 99m stannous pyrophosphate and Thallium - 201 scintigraphy of acute anterior myocardial infarcts in dogs. $\mathcal{F}$ Clin Invest 1976; 57: 1508-22.

12 Dewanjee MK, Kahn Pc, Dewanjee U, Connoll RJ. Mechanism of localization of Tc-99m labelled pyrophosphate and tetracycline in infarcted myocardium (abstract). $f$ Nucl Med 1975; 16: 525.

Requests for reprints to Dr František Duška, Department of Normal and Pathological Physiology, Charles University Faculty of Medicine, Šimkova 870, 50038 Hradec Králové, Czechoslovakia. 